\title{
High-Power Single Mode Operation of Hybrid \\ Ion-Implanted/Selectively-Oxidized VCSELs
}

G. Ronald Hadley, Kent D. Choquette, A. J. Fischer, K. M. Geib, A. A. Allerman, and J. J. Hindi

Center for Compound Semiconductor Science \& Technology Sandia National Laboratories

P.O. Box 5800

Albuquerque, NM 87185

(505)844-4015

(505)844-8985 (FAX)

grhadle@sandia.gov

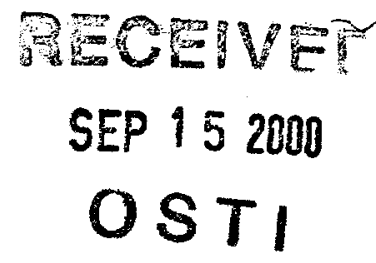

\begin{abstract}
We report the design and testing of a novel $850 \mathrm{~nm}$ hybrid vertical cavity laser employing ion implantation and selective oxidation to independently define the gain region and mode size for optimal high-power single-mode operation.
\end{abstract}




\section{DISCLAIMER}

This report was prepared as an account of work sponsored by an agency of the United States Government. Neither the United States Government nor any agency thereof, nor any of their employees, make any warranty, express or implied, or assumes any legal liability or responsibility for the accuracy, completeness, or usefulness of any information, apparatus, product, or process disclosed, or represents that its use would not infringe privately owned rights. Reference herein to any specific commercial product, process, or service by trade name, trademark, manufacturer, or otherwise does not necessarily constitute or imply its endorsement, recommendation, or favoring by the United States Government or any agency thereof. The views and opinions of authors expressed herein do not necessarily state or reflect those of the United States Government or any agency thereof. 


\section{DISCLAIMER}

Portions of this document may be illegible in electronic image products. Images are produced from the best available original document. 


\title{
High-Power Single Mode Operation of Hybrid Ion-Implanted/Selectively-Oxidized VCSELs
}

\author{
G. Ronald Hadley, Kent D. Choquette, A. J. Fischer, K. M. Geib, A. A. Allerman, and \\ J. J. Hindi \\ Center for Compound Semiconductor Science \& Technology \\ Sandia National Laboratories \\ P.O. Box 5800 \\ Albuquerque, NM 87185 \\ (505)844-4015 (505)844-8985 (FAX)
}

Selectively-oxidized vertical-cavity surface-emitting lasers have demonstrated record performance. However, due to the strong index confinement created by the low-index oxide layers, devices with large enough diameter to produce significant power virtually always operate in multiple transverse modes[1]. High-power single-mode operation is desirable in many applications such as optical storage and printing due to the ability to tightly focus the laser output. One method of providing the mode selectivity necessary to insure single mode operation in a large diameter VCSEL is to independently control the size of the gain region and that of the optical mode[2]. We first present numerical simulations that quantify this approach by predicting lateral mode discrimination for different sized gain apertures. These calculations are experimentally confirmed by the fabrication and testing of $850 \mathrm{~nm}$ VCSELs employing hybrid ion implantation/selective oxidation that produce a single-mode output of more than $5 \mathrm{~mW}$.

We performed VCSEL simulations using a $2 \mathrm{D}$ axisymmetric finite-difference code that solves for cavity eigenmodes including both mode shape and energy loss rate for a realistic VCSEL structure that includes gain and loss in the quantum well(s). We chose a VCSEL comprised of a $1-\lambda$ cavity containing a single 100 A quanturn well with 34 DBR pairs below and 21 above the cavity. Optical mode confinement resulted from two quarter-wave oxide layers positioned just above and below the cavity with fixed $10 \mu \mathrm{m}$ diameter. Gain in the quantum well was made uniform within some aperture radius and given a large negative value outside the aperture to simulate the unpumped quantum well. For each aperture diameter, the gain was set so that the fundamental mode was at threshold, and the modal loss of the most competitive higher-order modes computed. In Fig. 1, the loss has been normalized by the cold-cavity loss of the fundamental mode. Symbols plotted along the vertical axis correspond to the first-order radial mode having $\mathrm{m}=0$. These results show clearly that with a $10 \mu \mathrm{m}$ gain aperture there is virually no mode discrimination, but that as the diameter is reduced below the oxide diameter significant mode discrimination appears. Gain aperture reduction is of course limited by the resulting severalfold threshold increase predicted by the model (and observed experimentally).

This concept was realized in the laboratory by using conventional proton implantation to define a gain region independently from the size of the oxide aperture, as shown in Fig. 2. Devices with equal gain and oxide apertures lased multimode as expected. However, when the gain aperture was decreased to about half the oxide aperture, single mode 
operation ensued up to the device's peak output, in agreement with the simulations. For example, VCSELs with $6 \mu \mathrm{m}$ implant diameter and $12 \mu \mathrm{m}$ oxide diameter display the output characteristics shown in Fig. 3. This device lased single mode with $30 \mathrm{db}$ of side mode suppression up to its maximum output power of $5.2 \mathrm{~mW}$. Higher single-mode output power is expected from similar devices designed with more aggressive output coupling. Sandia is a multiprogram lab operated by Sandia Corporation for the U.S. Dept. of Energy under Contract DE-AC04-94AL85000.

\section{References}

[1] K. D. Choquette and K. M. Geib, "Fabrication and Performance of Vertical Cavity Surface Emitting Lasers", Chap. 5 in Vertical Cavity Surface Emitting Lasers, ed. C. Wilmsen, H. Temkin and L. Coldren, Cambridge University Press (Cambridge, UK) 1999.

[2] K. D. Choquette, A. A. Allerman, K. M. Geib and J. J. Hindi, "LithographicallyDefined Gain Apertures Within Selectively Oxidized VCSELs", CLEO2000, paper CtuL6, San Francisco, CA (May 2000).

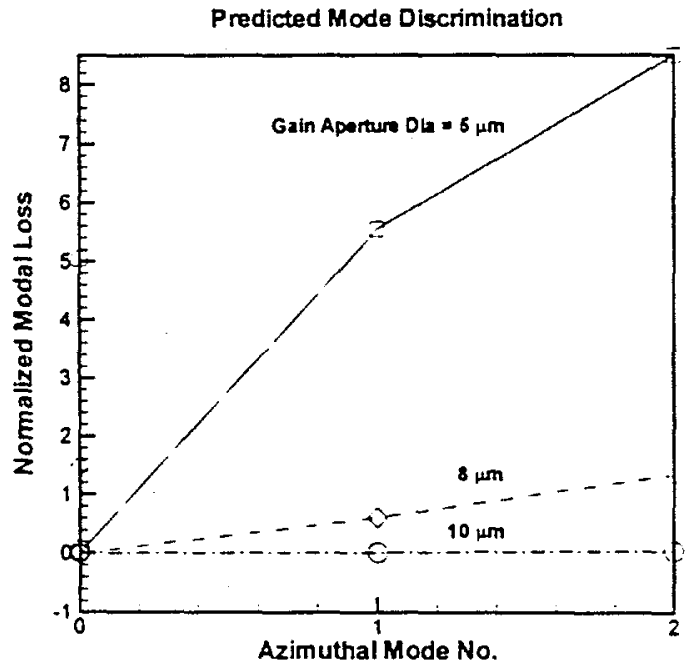

Fig. 1 Predicted modal loss for different high-order modes and gain apertures

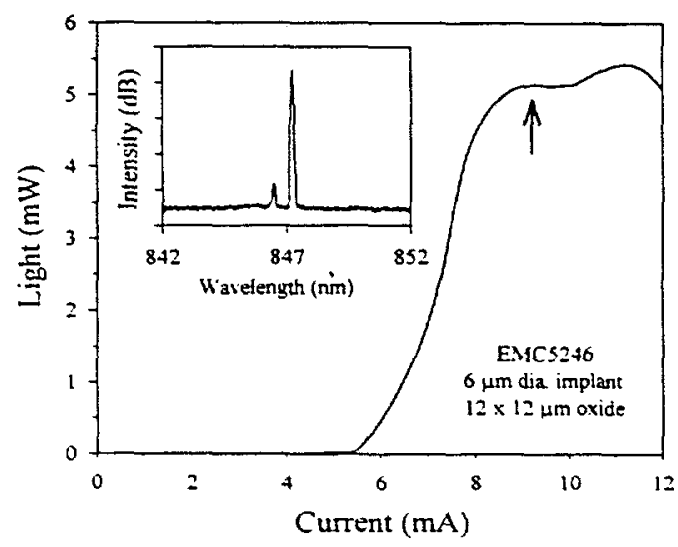

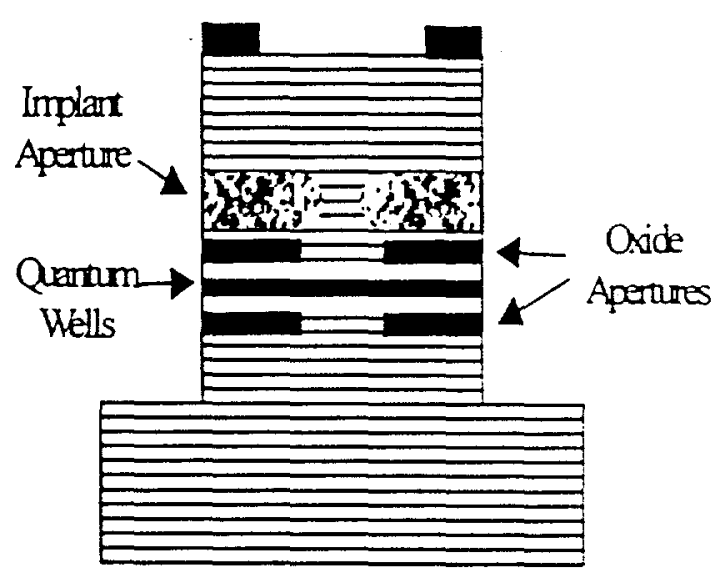

Fig. 2 Hybrid VCSEL schematic

Fig. 3 Measured $\mathrm{LI}$ curve for $6 \mu \mathrm{m}$ gain aperture and $12 \mu \mathrm{m}$ oxide aperture. Inset shows side-modesuppresion at current indicated by arrow. 